\title{
VO02 MONITORING RESERVOIR FLOW USING MAGNETOMETRY
}

MIKE F. MIDDLETON

Chalmers University of Technology, Department of Geology, 41296 Gotenborg, Sweden

\section{耳ratoduction}

It is well known that fluid flow in porous rocks has a concomitant electrokinetic effect (Morgan et al. 1989; Sprunt et al. 1994). The principal electrokinetic effect occurring in a flowing reservoir (i.e. reservoirs undergoing production) is the development of a streaming potential, due to the applied pressure drop across the reservoir. Wurmstich and Morgan (1994) have investigated the possibility of detecting pumping operations using streaming potential measurements at the surface and in nearby monitoring wells. Fitterman (1979) showed that streaming potential can give rise to a magnetic field under special circumstances. Fenoglio et al. (1995) have successfully modelled observed magnetic anomalies, associated with pressured fault zones, using the streaming potential distribution as the magnetic source. It is suggested in this paper that electrical potential distribution, associated with streaming potential effects in producing petroleum reservoirs, can give rise to observable magnetic anomalies, and it is proposed that these anomalies can be used to monitor hydrocarbon-water contacts.

\section{Theory}

The conventional theory for streaming potential $(\Delta \mathrm{V})$ states (Levine et al. 1976)

$$
\Delta V / \Delta P=\left[\varepsilon \zeta R_{f}\right] /\left[4 \pi \mu_{f}\right],
$$

where $\Delta \mathrm{P}$ is applied pressure difference, $\varepsilon$ is the dielectric constant, $\zeta$ is the zeta potential, $R_{f}$ is the pore fluid resistivity and $\mu_{\mathrm{f}}$ is the fluid viscosity. Jouniaux and Pozzi (1995) have shown that this simple relation can change significantly with confining pressures greater than about $50 \mathrm{MPa}$ (burial depths greater than about $2 \mathrm{~km}$ ), but this complication will be ignored for the present paper, as petroleum reservoirs are generally shallower than this.

The present theory is based on a modification of that proposed by Fitterman (1998).

The magnetic field $(\mathbf{B})$ produced by a current density $(\mathbf{J})$, due to an electrical potential distribution, is described by the Biot-Savart Law

$$
\mathbf{B}=\nabla \times \iiint_{V} d v\left[\mu_{0} \mathbf{J} / 4 \pi \mathrm{r}\right],
$$

where $v$ is volume, $\mu_{0}$ is the magnetic permeability of a vacuum, $r$ is distance, $(\nabla \mathbf{x})$ indicates the curl operator, and $\left(\iiint_{\mathrm{V}}\right)$ indicates a volume integral. Proceeding in the same fashion as Fitterman (1979, p. 6033-6035), but without the source image, an expression is found for the magnetic field due to the horizontal contact shown in Figure 1:

$B \approx B_{0} \ln \left\{\left[\left(d^{2}+a^{2}\right)^{1 / 2}-h\right]\left[\left(d^{2}+b^{2}\right)^{1 / 2}+h\right] /\left\{\left[\left(d^{2}+a^{2}\right)^{1 / 2}+h\right]\left[\left(d^{2}+b^{2}\right)^{1 / 2}-h\right]\right\}\right\}$,

where $B_{0}=\left\{\mu_{0} \varepsilon \zeta \Delta P / \mu_{w}\right\}\left\{R_{h y}\left(\mu_{w} / \mu_{h y}\right)-R_{w}\right\} /\left\{16 \pi^{2}\left(R_{r}+R_{o}\right)\right\}$, and $d^{2}=h^{2}+z^{2}, R_{h y}$ is the resistivity of the hydrocarbon, $\mu_{h y}$ is the viscosity of the hydrocarbon, $R_{W}$ is the resistivity of the formation water, $\mu_{W}$ is the viscosity of the formation water, $R_{r}$ is the resisitvity of the hydrocarbonfilled rock and $R_{0}$ is the resisitivity of the water-filled reservoir rock, and the other petrophysical 
constants as in equations (1) and (2). The magnetic field due to the conductive contacts of the sides and top of the reservoir can also be calculated using equation (2), see also Fitterman $(1979$, p. 6033), and may be of the same order of magnitude. Figure 1 shows the total magnetic field anomaly, measured in the well, due to the base of the reservoir alone (equation 3 ) in an hypothetical well drilled $100 \mathrm{~m}$ beyond an oil-water contact. For this example, $R_{\mathrm{W}}=0.1 \Omega \mathrm{m}, \mathrm{R}_{\mathrm{hy}}=500 \Omega \mathrm{m}, \mathrm{R}_{\mathrm{r}}=50 \Omega \mathrm{m}$, $\mathrm{R}_{\mathrm{O}}=2.5 \Omega \mathrm{m}, \varepsilon \zeta / \mu_{\mathrm{w}}=50 \mathrm{mV} / \Omega \mathrm{m}$ atm, $\mu_{\mathrm{w}} / \mu_{\mathrm{hy}}=1.7$ and $\Delta \mathrm{P}=100 \mathrm{psi}$. It is seen that the magnetic response due to the contact is approximately $300 \mathrm{nT}$, which is well within the resolution of current magnetometry, and also that the contact is centred on the anomaly peak.

\section{Conclusions}

The theory and example shown in this paper strongly suggests that the monitoring of gas-oil and oilwater contacts within an hydrocarbon reservoir can provide valuable information on the fluid distribution within the reservoir. In keeping with the vision of "Reservoir Geophysics - The Road Ahead", magnetic monitoring of fluid flow presents an exciting future development area for geophysical applications in the hydrocarbon production sphere.

\section{References}

Fenoglio, M.A., Johnston, M.J.S. \& Byerlee, J.D. 1995. Magnetic and electric fields associated with changes in high pore pressure in fault zones: Application to the Loma Prieta ULF emissions. Journal of Geophysical Research 100, 12951-12958.

Fitterman, D.V. 1979. Calculations of self-potential anomalies near vertical contacts. Geophysics 44, 195-205.

Jouniaux, L. \& Pozzi, J-P. 1995. Streaming potential and permeability of saturated sandstones under triaxial stress: Consequences for electrotelluric anomalies prior to earthquakes. Journal of Geophysical Research 100, 10197-10209.

Levine, S., Marriott, J.R., Neale, G. \& Epstein, N. 1975. Theory of electrokinetic flow in fine cylindrical capillaries at high zeta-potentials. Journal of Colloidal and Interface Science 52, 136-149.

Morgan, F.D., Williams, E.R. \& Madden, T.R. 1989. Streaming potential properties of Westerly Granite with applications. Journal Geophysical Research 94, 12449-12461.

Sprunt, E.S., Mercer, T.B. \& Djabbarah, N.F. 1994. Streaming potential from multiphase flow. Geophysics 59, 707-711.

Wurmstich, B. \& Morgan, F.D. 1994. Modeling of streaming potential responses caused by oil well pumping. Geophysics 59, 46-56.

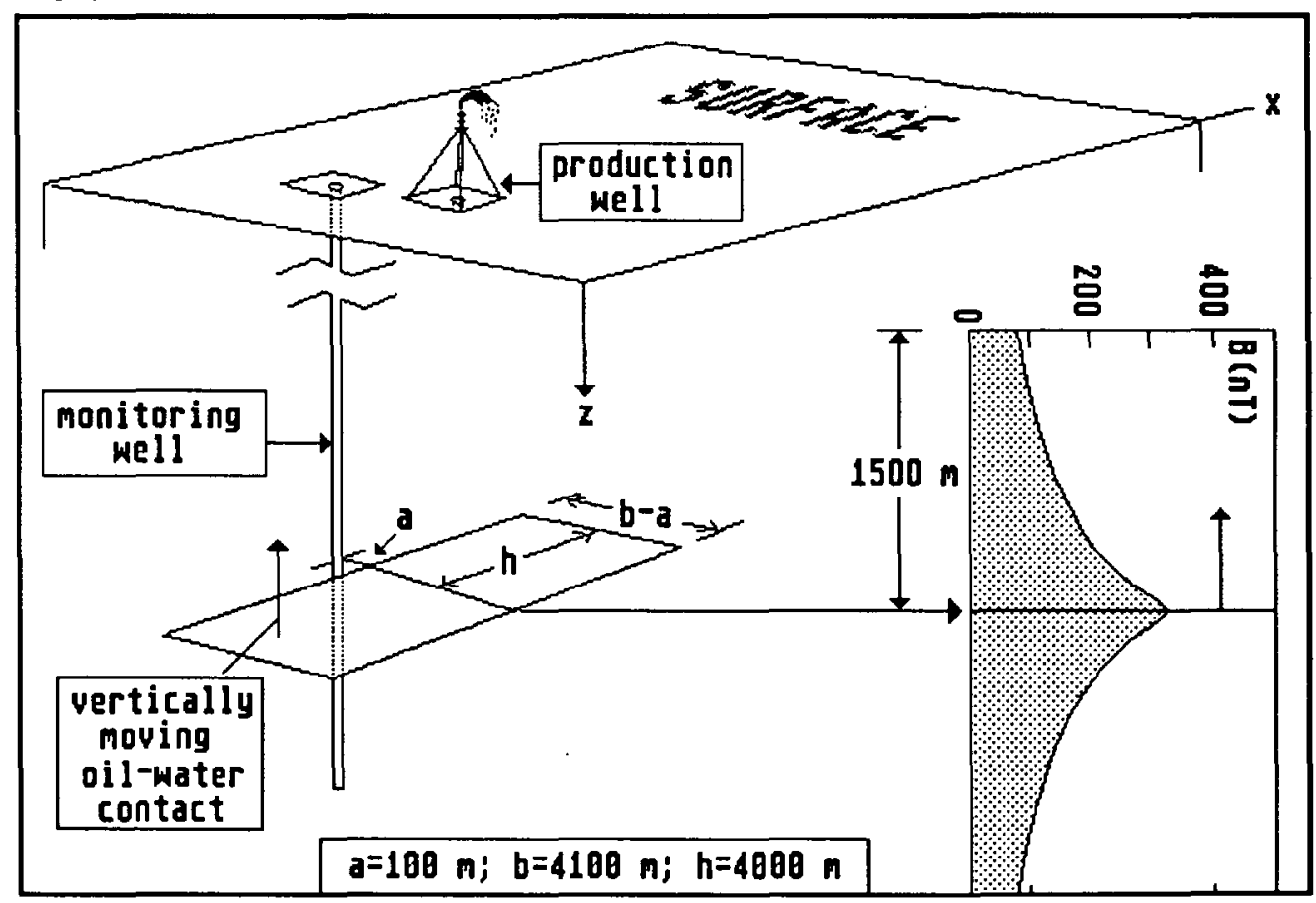

Figure 1: Model of streaming potential induced magnetic anomaly at oil-water contact. 